\title{
Okul Öncesi Eğitim Programının 21. Yüzyıl Becerileri ve STEAM Eğitimi Bağlamında İncelenmesi
}

\author{
Servet Kardeş
}

Özel Eğitim Bölümü, Eğitim Fakültesi, Van Yüzüncü Yıl Üniversitesi, Van, Türkiye

Sorumlu Yazar: Servet Kardeş, kardesservet@gmail.com

Makale Türü: Araştırma Makalesi

Bilgilendirme: Bu makale, VII. International Eurasian Educational Research Congress'sinde bildiri olarak sunulmuştur.

Kaynak Gösterimi: Kardeş, S. (2020). Okul öncesi eğitim programının 21. yüzyıl becerileri ve STEAM eğitimi bağlamında incelenmesi. Eğitimde Kuram ve Uygulama, 16(2), 109-119. doi: 10.17244/eku.703361

\section{Analysis of Preschool Education Program in the Context of 21st Century Skills and STEAM Education}

\author{
Servet Kardeş
}

Department of Special Education, Faculty of Education, Van Yuzuncu Yil University, Van, Turkey

Corresponding Author: Servet Kardeş, kardesservet@gmail.com

Article Type: Research Article

Acknowledgement: This article was presented in VII. International Eurasian Educational Research Congress.

To Cite This Article: Kardeş, S. (2020). Okul öncesi eğitim programının 21. yüzyıl becerileri ve STEAM eğitimi bağlamında incelenmesi. Eğitimde Kuram ve Uygulama, 16(2), 109-119. doi: 10.17244/eku.703361 


\title{
Okul Öncesi Eğitim Programının 21. Yüzyıl Becerileri ve STEAM Eğitimi Bağlamında İncelenmesi
}

\author{
Servet Kardeş \\ Özel Eğitim Bölümü, Eğitim Fakültesi, Van Yüzüncü Yıl Üniversitesi, Van, Türkiye \\ ORCID: http://orcid.org/0000-0002-4230-6628
}

\begin{abstract}
$\ddot{\mathbf{O z z}}$
Bireyin bütüncül gelişimi ve iyi becerilere sahip olabilmesi için erken çocukluk yıllarında iyi bir eğitim alması gerekir. Erken çocukluk yıllarında çocuklara verilen eğitime temel oluşturan programın kalitesi ve içeriği bu anlamda önem taşımaktadır. Bu araştırmada 2013 okul öncesi eğitim programının 21. yüzyıl becerileri ve STEAM eğitimi açısından incelenmesi amaçlanmıştır. Araştırmada nitel araştırma yöntemlerinden doküman analizi kullanılmıştır. Verilerin analizinde ise betimsel analiz yöntemi kullanılmış ve verilerin analizinde, nitel analiz programı olan MAXQDA kullanılmıştır. 2013 Okul Öncesi Eğitim Programı kapsamında, okul öncesi eğitiminin temel ilkeleri, gelişim özellikleri, kazanım ve göstergeler, okul öncesi eğitiminin planlanması, uygulanması, değerlendirilmesi bölümleri incelenmiştir. Araştırma sonucunda 2013 okul öncesi eğitim programının 21. Yüzyıl becerilerinden olan karakter özellikleri ve yetkinlik üzerinde durduğu özellikle iletişim temelli bir program olduğu ancak bilgi, teknoloji ve medya okuryazarlığı anlamında yetersiz olduğu görülmüştür. Bununla birlikte programın STEAM eğitimi bağlamında sanat eğitimini vurguladığı, bilim ve matematik üzerinde durduğu, ancak mühendislik ve tasarım konusunda hiçbir içeriğe sahip olmadığ 1 görülmüştür. Elde edilen sonuçlar doğrultusunda programın 21. yüzyıl becerileri ve STEAM bağlamında yeniden değerlendirilerek revize
\end{abstract} edilmesi önerilebilir.

\section{Makale Bilgisi}

Anahtar kelimeler: 21. Yüzyıl

becerileri, Erken çocukluk, Okul öncesi, Okul öncesi

eğitim programı, STEAM

Makale Geçmişi:

Geliş: 13 Mart 2020

Düzeltme: 19 Temmuz 2020

Kabul: 6 Ağustos 2020

Makale Türü: Araştırma

Makalesi

\section{Analysis of Preschool Education Program in the Context of 21st Century Skills and STEAM}

\section{Education}

\section{Abstract}

In order for an individual to have good skills and holistic development, he/she needs to have a good education in early childhood years. The importance of early childhood, which forms the basis of an individual's education, is well-known. The quality and content of the program, which forms the basis of education given to children in early childhood, is important in this sense. In this study, it is aimed to examine the 2013 preschool education program in terms of 21 st century skills and STEAM education. Document analysis, one of the qualitative research methods, was used in the research. Descriptive statistics method was used to analyze the data, and the qualitative analysis program MAXQDA was used. Within the 2013 Preschool Education Program, the basic principles, development characteristics, achievements and indicators of preschool education, planning, implementation, evaluation sections of pre-school education were examined. As a result of the research, it was found that 2013 pre-school education program is a communicationbased program that focuses on character traits and competence, which are among the $21 \mathrm{st}$ century skills, but it is insufficient in terms of information technology and media literacy. However, it was seen that the program emphasized art education in the context of STEAM education, focused on science and mathematics, but had no content in engineering and design. In line with the results, it may be suggested to revise the 2013 preschool education program in the context of 21 st century skills and STEAM.
\end{abstract}

\author{
Article Info \\ Keywords: 21 st century skills, \\ Early childhood, Preschool, \\ Preschool education program, \\ STEAM
}

Article History:

Received: 13 March 2020

Revised: 19 July 2020

Accepted: 6 Ağustos 2020

Article Type: Research Article

Not: Bu çalışmada, erişime açık dokumanlar analiz edilmiş olup bu nedenle veri toplamada ayrıca bir etik onay süreci işletilmemiştir. 


\section{Extended Summary}

\section{Introduction}

Today, because of the insufficient education they receive, teachers give education based on memorization and passive learning and are unable to structure the learning environment required. Therefore, teachers may be inadequate in the use of curiosity-based learning approaches and information and communication technologies such as social media, blogs, mobile technology. However, teachers have a vital role in combining the 21 st century skills with the educational process. Research revealed that teachers are willing to implement STEAM education but need information and support in this regard. Therefore, it is important to support teachers with a strong and effective program and to guide the preschool teachers.

Use of information and technology became very important in the 21 st century. In order for the individual to have access to qualified information and use technology for his life and development, she/he must have some skills. 21 st century skills refer to skills that will enable individuals to be more competitive and self-sufficient in the world of technology. In order to have good skills and holistic development of an individual, he/she needs to have a good education in early childhood years. The importance of early childhood, which forms the basis of an individual's education, is known. Today, because of the insufficient education they receive, teachers give education based on routine and passive learning and are unable to structure the learning environment required for 21 st century skills. The quality and content of the program, which forms the basis of education given to children in early childhood, is important in this sense.

In this context, answers to the following questions were sought in the research.

1. How is the 21 st century skills included in the 2013 pre-school education program?

2. How is STEAM concepts and practices included in the 2013 pre-school education program?

\section{Method}

This research is a qualitative study aiming to examine the 2013 pre-school education program in terms of STEAM education and 21st century skills. Document analysis, one of the qualitative research methods, was used in the research. Documents of the study were preschool education program (2013) and preschool education activity book. The main purpose in document review was to analyse the content of written texts containing information about the targeted phenomenon or cases. Descriptive analysis was used while analysing data, and the qualitative analysis program MAXQDA was used. Within the 2013 Preschool Education Program, the basic principles, development characteristics, achievements and indicators of preschool education, planning, implementation, evaluation sections of pre-school education were examined. The concepts related to the 21 st century skills included in the 2013 preschool education program and the concepts related to STEAM education were first read in detail and the codes were determined. In the second stage, 21 century skills and concepts related to STEAM, for example collaboration, creativity, problem solving, designing, engineering were searched in the program and the contents of the related fields were checked again. The codes that appeared under the themes were interpreted by the researcher.

In order to ensure the reliability of the analysis, the coding was done independently by two researchers. In order to determine the consistency of the individual coding, reliability $=[$ (compliance) $/($ compatibility + incompatibility $)$ ]x100 formula was used.

\section{Findings}

In this section, the content of 2013 pre-school education program is examined in the context of 21 st century skills and STEAM related concepts. The information obtained is presented below.

Preschool education program was mostly focused on entrepreneurship (17), responsibility (14), cultural awareness (12), research (7) and courage (7). When we look at developing competence skills in children, it is seen that the most emphasis is on communication (31), creativity (15) and problem-solving skill (9). It is seen that literacy skill is passed once in the program; however, information, media and technology literacy are not included in the program. It was observed that STEAM skills (25) were mostly included as art education (14), science (5) and mathematics (3) skills were included in the program, but engineering, design and innovation were not included in the program.

\section{Discussion and Conclusion}

As a result of the research, it was found that 2013 pre-school education program is a communication-based program that focuses on character traits and competence, which are among the 21 st century skills, but it is insufficient in terms of information technology and media literacy. However, it was seen that the program emphasized art education in the context of STEAM education, focused on science and mathematics, but had no content in engineering and design. In line with the results, it may be suggested to revise the 2013 preschool education program in the context of 21 st century skills and STEAM. 


\section{Giriş}

Hızla değişen dünya için yeni beceriler, yaratıcı fikirler ve yeni çözümlere ihtiyaç var. İklim değişikliği, hızla tükenen kaynaklar ve çevre kirliliği acil eylemler ve sürdürülebilir çözümler gerektirmektedir. Bilimsel bilgi insanlığa yeni firsatlar ve kolaylıklar sağlarken birçok alanda da yıkıcı etkiler ortaya koyabilmektedir. Özellikle biyoteknoloji ve yapay zekâdaki gelişmeler insanlığın nereye doğru gittiği ve güvenlik endişeleri ile ilgili soruları daha görünür kılmaktadır. İnsanlığın geleceğinin daha iyi olması için yeni ve yaratıcı ekonomik, sosyal ve kurumsal modeller geliştirilmelidir. Bununla birlikte göç, kentleşme ve artan sosyal kültürel çeşitlilik kentleri ve toplumları yeniden şekillendirmektedir. Sosyal gelir adaletsizliği, çatışma ortamları, istikrarsızlık, ekonomik krizler, popülist politikalar ve savaşlar dünya da yeni bir dönemin başlamasına sebep olmuştur. Bu durum eşitsizliği, sosyal ayrışmayı ve kaynakların tüketimini hizlandırmaktadır (OECD, 2018).

21. yy'da bilgi ve teknoloji kullanımı çok önemli hale geldi. Bireyin yaşamı ve gelişimi için nitelikli bilgiye ulaşabilmesi ve teknolojiyi kullanabilmesi için ise bazı becerilere sahip olması gerekir. 21. yy becerileri, teknoloji dünyasında bireylerin kendilerine yetebilecek ve daha rekabetçi olmalarını sağlayacak becerileri ifade eder (O'Neal, Gibson, \& Cotten, 2017). 21. yy becerileri genel olarak iş birliği, iletişim, dijital okuryazarlık, problem çözme, kritik düşünme becerisi, yaratıcılık ve verimlilik olarak ifade edilmektedir (Voogt \& Roblin, 2012). Partnership for 21st Century Skills (2008) ise 21. yy becerilerini üç grupta incelemektedir. Bu beceriler; Öğrenme becerileri (yaratıcılık ve yenilikçilik, problem çözme ve kritik düşünme becerisi, iletişim ve işbirliği), okuryazarlık (Bilgi, medya ve teknoloji), ve yaşam becerileri (esneklik ve uyum, sosyal ve kültürel beceriler, liderlik, üretkenlik, hesap verebilirlik ve sorumluluk alma) olarak ifade edilmektedir. Kereluik, Mishra, Fahnoe ve Terry (2013) ise 21. yy becerilerinin temel bilgi (dijital okuryazarlık, disiplinler arası bilgi, bilgi okuryazarlığı), yeterlilik (yaratıcılık ve yenilikçilik, kritik düşünme ve problem çözme, iletişim ve işbirliği) ve insani bilgiyi (yaşam becerileri, etik ve duygusal farkındalık, kültürel yeterlilik) içerdiğini ifade etmişlerdir. Lamb, Maire ve Doecke (2017) bu yeterliliklere üst biliş ve motivasyonu eklemişlerdir. Beers (2011) iletişim, iş birliği, bilgi yönetimi, kariyer ve yaşam becerileri, kültürel farkındalık, eleştirel düşünme, teknolojinin etkin kullanımı, problem çözme, yaratıcılık ve orijinal fikirler üretmenin 21. yy becerileri olduğunu ifade etmektedir. OECD (2018) öğrenme çerçevesi 2030 raporunda bilgi (disipliner, disiplinler arası, epistemik) beceri (Bilişsel, üst bilişsel, sosyal duygusal, fiziksel ve pratik beceriler) tutum ve değerler (Kişisel, yerel, toplumsal ve global) üzerinde durmaktadır. Eğitim sistemi içerisinde yer alan bireyin iyi bir okuryazar (temel, sağlık, bilgi ve dijital okuryazar) olması gerektiği, sorumluluk alabilmesi, yeni değerler ortaya koyabilmesi ve sorunlara çözüm üretebilmesi gerektiği ifade edilmiştir.

Günümüzde öğretmenler aldıkları eğitimin yetersiz olmasından dolayı ezbere ve pasif öğrenmeye dayalı eğitim vermekte ve 21. yy becerileri için gerekli olan öğrenme çevresini yapılandırmakta yetersiz kalmaktadırlar (O'Neal et al., 2017). Örneğin öğretmenler merak temelli öğrenme yaklaşımları ve bilgi ve iletişim teknolojilerinin (sosyal medya, bloglar, mobil teknoloji vb.) kullanımında yetersiz kalabilmektedirler (Häkkinen, Järvelä, Mäkitalo-Siegl, Ahonen, Näykki, \& Valtonen, 2017). Oysa 21. yy becerilerinin okuldaki eğitim süreciyle birleştirilerek çocuğa kazandırılmasında öğretmenlerin hayati rolü vardır (Cansoy, 2018). Ayrıca günümüz eğitim sisteminde 21. yy becerileri kadar önem verilen bir diğer eğitim ise STEAM eğitimidir. STEAM eğitimi ile bireylerin eleştirel düşünme, yaratıcılık, işbirliği ve iletişim becerilerinin önemli düzeyde desteklendiği ifade edilmektedir. Bu anlamda McClure ve diğerleri (2017) yaptıkları araştırmada öğretmenlerin STEAM eğitimini uygulamada istekli oldukları ancak bu konuda bilgiye ve desteğe ihtiyaçları olduğunu ortaya koymuşlardır.

STEAM (Science, Technology, Engineering, Art and Mathematics) bilim, teknoloji, mühendislik, sanat ve matematik disiplinlerini içeren ve modern eğitimin önemli bir öğretim tekniği olarak görülen, yaparak yaşayarak öğrenmeye dayanan, iş, okul ve toplum arasında bağlantıyı sağlayan disiplinler arası bir yaklaşımdır (Tsupros, Kohler, \& Hallinen, 2009). Gelişen teknoloji, değişen ihtiyaçlar ve yeni gereksinimlerle birlikte daha nitelikli bireylere, takım halinde çalışmaya ve teknolojik aletleri kullanabilme becerisine sahip bireylere olan ihtiyaç artmıştır. STEAM çocuklara proje temelli, iş birliği içinde çalı̧̧ma ve yaparak öğrenme deneyimi sunarak somut deneyimler elde etmeleri ve etraflarındaki dünyayı anlamlandırmaları için firsatlar sunar. STEAM eğitimi alan öğrenciler, fen ve matematik disiplinleriyle öğrendikleri bilgiyi mühendislik ve teknolojiden faydalanarak bir sorun alanı için çözüm oluşturabilirler (Kennedy \& Odell, 2014). Çocuklar doğal olarak günlük keşiflerinde, etkileşimlerinde, oyunlarında ve yeni deneyimlerinde STEAM uygulamalarını kullanmaktadırlar. Çocuğun STEAM deneyimleri ve uygulamaları ile çocuğun gelecekteki başarısı arasında pozitif ilişki vardır (Bertrand, 2019; National Center On, 2018). Ayrıca başarı düzeyi yüksekokullara bakıldığı zaman STEAM uygulamalarını başarılı bir şekilde bütün eğitim kademelerinde kullandıkları görülmektedir. STEAM eğitiminin okul öncesi dönemden itibaren çocuklara verilmesi gerektiğini ifade eden çalışmalar vardır (Jamil, Linder, \& Stegelin, 2018; Katz, 2010; McClure et al., 2017; Soylu, 2016). Erken yıllarda çocukların resistörler, sensörler ve motorlarla karşılaştığı ve çalıştığı görülmektedir (McClure et al., 2017). Bu yaklaşım çocukların derin düşünme becerilerine katkıda bulunmakta ve araştırma temelli projelerde çalışmalarını sağlamaktadır.

Öğretmenler STEAM eğitiminin 21. yy becerilerini destekleyeceğini, problem çözme becerisi ve bilimsel süreç becerilerini geliştireceğini ve öğrencilerin derse olan ilgisini arttıracağını düşünmektedirler (Uğraş, 2017). Ayrıca öğretmenlerin STEAM farkındalıklarının geliştirilmesi için eğitilmeleri ve alan gezileri ya da bilim kampları 
düzenlenmesi gerektiği ifade edilmektedir (Koyunlu-Ünlü \& Dere, 2019). Yalçın (2018) yaptığı araştırmada 21. yy becerilerinin bireylere kazandırılmasında durumsal yargı testleri, bilgisayar simülasyonları, beceri ve yetenek geçmişi gibi değerlendirme yöntemlerinin kullanılması gerektiği ancak bu yöntemlerin fazla bilinmemesinden dolayı bu yönlü bir değerlendirmenin yapılamadığını ortaya koymuştur.

Okul öncesi eğitim programının, değerler eğitimi (Aral \& Kadan, 2018), sağlık (Sönmez \& Seyhan, 2016), çocuğun katılım hakkı (Gürkan \& Koran, 2014), çevre eğitimi (Gülay \& Ekici, 2010), değerlendirme (Sapsağlam, 2013), cinsel eğitim (Deniz \& Yıldız, 2018) gibi çok farklı boyutlarda incelenmesine rağmen 21. yy becerileri ve STEAM eğitimi açısından yeterince incelenmediği görülmüştür. Tuğluk ve Özkan (2019) okul öncesi eğitimi programının 21. yy becerilerini içerme durumunu akademisyen görüşleriyle ortaya koymuş ancak bu araştırmada programın kendisi yaygın bir nitel analiz programı ile 21. yy becerileri ve STEAM açısından detaylı şekilde incelenmiştir. Ayrıca eğitim politikalarını belirleyenler açısından programın, 21. yy öğretenine rehber olması ve 21. yy öğreneni için gerekli olan becerileri kazandırması açısından yeniden yapılandırılması ya da revize edilmesi gerekebilir. Dolayısıyla bu araştırmanın eğitim politikalarını belirleyenlere ve araştırmacılara katkı sunacağı düşünülmektedir.

\section{Çalışmanın Amacı ve Önemi}

Yaşamın her alanında hızla bir değişim ve dönüşümün yaşandığı 21. yy da yetiştirilecek bireylerin sahip olması gereken becerilerde farklılık göstermiştir. Bu farklılıklar eğitim sistemlerinde bir dönüşüm ve yenilenme hareketini başlatmıştır. $\mathrm{Bu}$ değişim çağın ihtiyaç ve gereksinimlerini karşılayacak bireylerin eğitimlerinde akademik beceriler kadar bilim, teknoloji, mühendislik ve matematik becerilerinin de yer alması gerektiğini göstermiştir. Bireyin gelişiminin temellerinin atıldığı ve karakterinin şekillendiği erken çocukluk yıllarının önemi bilinmektedir. Bu dönemde 21. yy becerilerine sahip bireylerin yetiştirilebilmesi için öğretmen kadar öğretmenlere rehberlik eden programlarında oldukça önemli olduğu söylenebilir. Alanda yapılan araştırmalara bakıldığında Yaşar-Ekici, Bardak ve Yousef-Zadeh (2018) yaptıkları derleme çalışmasında okul öncesi dönemde STEM eğitimi hakkında bilgi vermişlerdir. Bardak ve Kaplan (2020) ise erken çocuklukta STEM eğitimi kimliğini teşvik etmek başlıklı çeviri yayın yapmışlardır. Polat ve Bardak (2019) yaptıkları derleme çalışmada erken çocukluk döneminde STEM uygulamaları üzerinde durmuşlardır. Buradan hareketle erken çocukluk döneminde STEM uygulamaları ile ilgili çalışmaların daha çok alan yazın taraması şeklinde derleme ve çeviri çalışmalar olduğu görülmüştür. Bundan dolayı bu araştırmada 2013 okul öncesi eğitim programının 21. yy becerileri ve STEAM eğitimi açısından değerlendirilmesi amaçlanmıştır. Bu anlamda bu araştırmanın erken çocuklukta STEM eğitimi alan yazınına katkıda bulunacağı düşünülmektedir. Bu bağlamda araştırmada aşağıdaki sorulara cevap aranmıştır:

1. 2013 okul öncesi eğitim programında 21. yy becerilerine yer verme durumu nasıldır?

2. 2013 okul öncesi eğitim programında STEAM kavramlarına ve uygulamalarına yer verme durumu nasildır?

\section{Araştırmanın Modeli}

Yöntem

Bu araştırma, 2013 okul öncesi eğitim programını 21. yy becerilerine ve STEAM eğitimine yer verme durumu açısından incelemeyi amaçlayan nitel bir çalışmadır. Nitel araştırmalar olayların ve durumlara ilişkin algıların doğal ortamında, bütüncül bir yaklaşım tarzıyla ortaya konulduğu çalışmalardır (Yıldırım \& Şimşek, 2013). Araştırmada 2013 okul öncesi eğitim programının 21. yy becerilerine ve STEAM kavramları yer verme durumu bütüncül olarak ortaya konmaya çalışılmıştır. Araştırmada nitel yaklaşımın tercih edilme nedeni yenilikçiliğe ve araştırmanın tasarladığı çerçevede çalışmaya daha fazla imkân tanımasıdır (Creswell, 2009). Nitel araştırmada gözlem, görüşme ve doküman analizi gibi nitel veri toplama yöntemleri kullanılır (Merriam \& Tisdell, 2015). Bu araştırmada veriler nitel veri toplama yöntemlerinden doküman analizi ile toplanmıştır. Betimsel analiz yöntemi kullanılmıştır. Betimsel analiz, çeşitli veri toplama teknikleri ile toplanmış verilerin daha önceden belirlenmiş temalar çerçevesinde özetlenmesi ve yorumlanmasına dayanan bir analiz yöntemidir (Yıldırım \& Şimşek, 2013).

\section{Veri Toplama Araçları}

Araştırmada veri toplama aracı olarak dokümanlardan yararlanılmıştır. Çalışmanın dokümanları; okul öncesi eğitim programı (2013) ile okul öncesi eğitim etkinlik kitabıdır. Bu araştırmada doküman analizi yöntemi kullanılmıştır. Doküman incelemesinde temel amaç araştırılması hedeflenen olgu ya da olgular hakkında bilgi içeren yazılı metinlerin içeriğinin derinlemesine incelenmesidir (Yıldırım \& Şimşek, 2013). Doküman analizinde araştırmacı analize başlamadan önce bazı kategoriler oluşturur (Fraenkel, Wallen, \& Hyun, 2011). Araştırmada oluşturulan kategoriler okuryazarlık becerileri, karakter özellikleri, yetkinlik ve STEAM becerileri olmuştur. Bu temaların altında dijital okuryazarlık, bilgi okuryazarlığı, iş birliği, yaratıcılık, problem çözme, sorumluluk alma, fen, matematik, mühendislik, tasarım gibi kodlar yer almıştır. 


\section{Verilerin Analizi}

Araştırmanın planlanması aşamasında tema ve alt kodlar önceden belirlendiğinden bu çalışmada betimsel analiz kullanılmıştır. 21. yy becerileri için karakter özellikleri (girişimcilik, sorumluluk, kültürel farkındalık, merak, araştırma, cesaret) yetkinlik (iletişim, yaratıcılık, problem çözme, işbirliği, eleştirel düşünme) ve okuryazarlık (bilimsel okuryazarlık, medya okuryazarlığı, teknoloji okuryazarlığı) temaları kullanılmış, STEAM için ise bilim, teknoloji, mühendislik, sanat ve matematik temaları kullanılmıştır. Araştırmada verilerin analizi için veriler önce hazırlanmış ve düzenlenmiştir. Verilerin tamamı okunarak incelenmiş ve verilerin belirlenen temalar altında kodlanmasına başlanmıştır. Verilerin analizinde nitel veri analiz programı olan MAXQDA 11 kullanılmıştır. 2013 okul öncesi eğitim programında yer alan 21. yy becerileri ile ilgili kavramlar ve STEAM eğitimi ile ilgili kavramlar ilk önce detaylı bir şekilde okunmuş ve kodlar belirlenmiştir. İkinci aşamada 21 yy becerileri ve STEAM ile ilgili kavramlar örneğin iş birliği, yaratıcılık, problem çözme, tasarlama, mühendislik gibi birebir programda aranmış ve ilgili alanların içerikleri tekrar kontrol edilmiştir. Daha sonra temalar altında ortaya çıkan kodlar araştırmacı tarafından yorumlanmıştır (Creswell, 2009). Okul Öncesi Eğitim Programı kapsamında, okul öncesi eğitiminin amaçları, okul öncesi eğitimin önemi, programın tanıtımı, temel ilkeler, gelişim özellikleri, kazanım ve göstergeler, okul öncesi eğitimde planlanma ve uygulanma, değerlendirme bölümleri ve ayrıca okul öncesi eğitim etkinlikleri kitabı incelenmiştir.

Analizin güvenirliğini sağlamak amacıyla kodlamalar birbirinden bağımsız olarak iki araştırmacı tarafindan yapılmıştır. Ayrı ayrı yapılan kodlamaların tutarlıı̆ı̆ını belirlemek amaciyla güvenirlik $=[($ uyum $)($ uyumluluk + uyumsuzluk) $] \times 100$ formülü kullanılmıştır. Araştırmacılar arasındaki uyuşma yüzdesi 84,6 olarak hesaplanmıştır. Uyuşma yüzdesi araştırmacılar arasındaki tutarlılığın yüksek düzeyde olduğunu göstermektedir. Uyuşma olmayan kodlamalarda ise araştırmacılar kendi aralarında tartışarak uzlaşmaya varmıştır.

\section{Bulgular}

Bu bölümde 2013 okul öncesi eğitim programı içeriği 21. yy becerileri ve STEAM ile ilgili kavramlar bağlamında incelenmiştir. Elde edilen bilgiler şekiller ve tablolar ile aşağıda sunulmuştur.

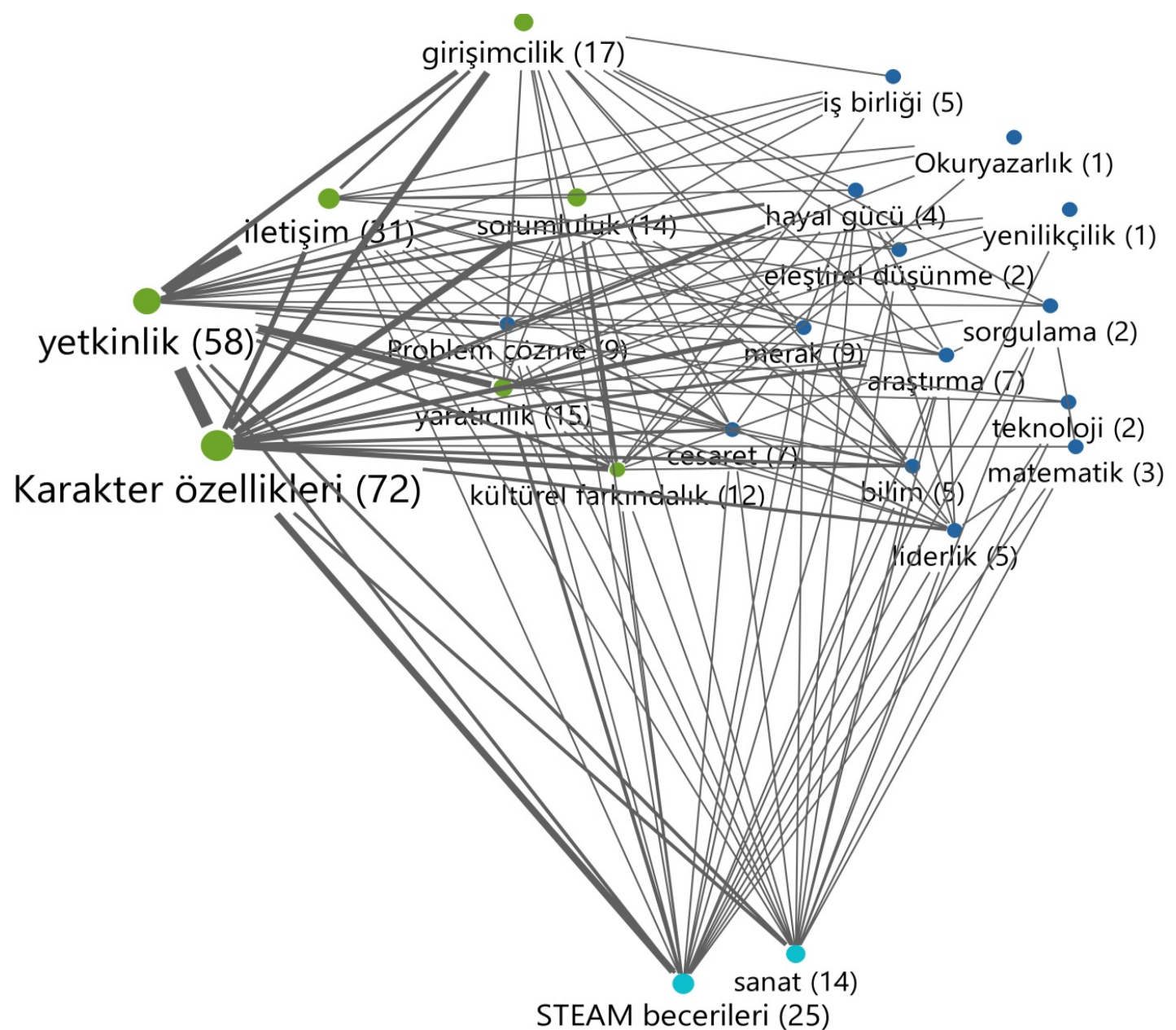

Şekil 1. 21. yy becerileri ve STEAM ile ilgili kavramlar

Şekil 1'de görüldüğü gibi okul öncesi eğitim programının en fazla girişimcilik (17), sorumluluk (14), kültürel farkındalık (12), araştırma (7) ve cesaret (7) üzerinde durduğu görülmektedir. Çocuklarda yetkinlik becerisini 
geliştirmeye baktığımızda ise en fazla iletişim (31), yaratıcılık (15), ve problem çözme becerisi (9) üzerinde durulduğu görülmektedir. Okuryazarlık becerisini programda bir defa geçtiği bunun dışında bilgi, medya ve teknoloji okuryazarlığının programda yer almadığı görülmektedir. STEAM becerilerinin (25) yoğunluklu olarak sanat eğitimi (14) şeklinde yer aldığı, bilim (5) ve matematik (3) becerilerinin programda yer aldığı ancak mühendislik, tasarım ve yenilikçiliğin programda yer almadığı görülmektedir.

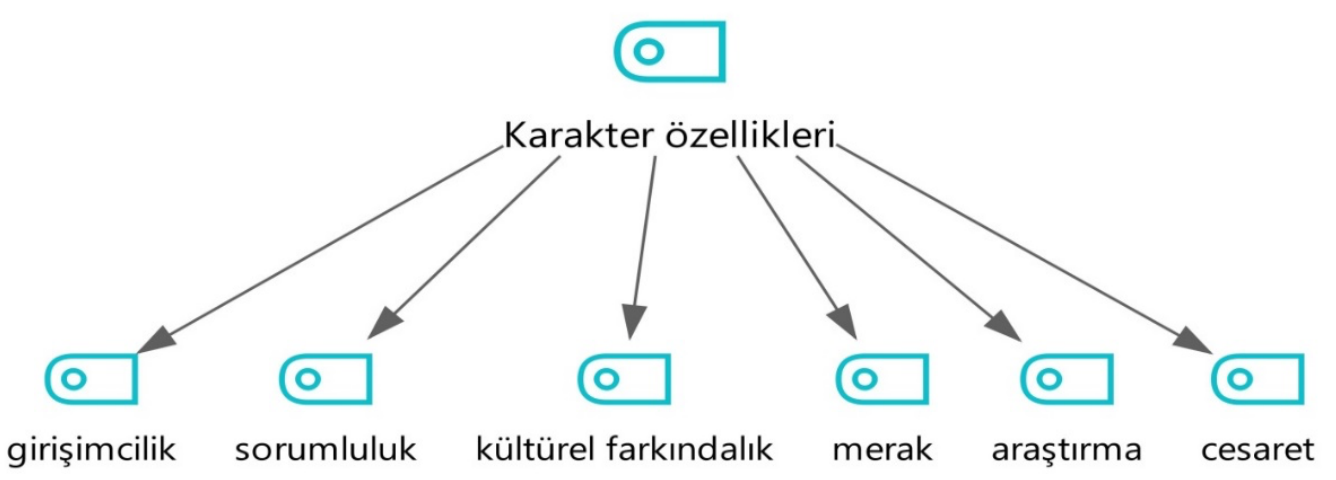

Şekil 2. Programda en çok yer alan karakter özellikleri

Şekil 2'de görüldüğü gibi programda en çok yer alan karakter özellikleri sırasıyla girişimcilik, sorumluluk, kültürel farkındalık, merak, araştırma ve cesaret olarak yer almıştır.

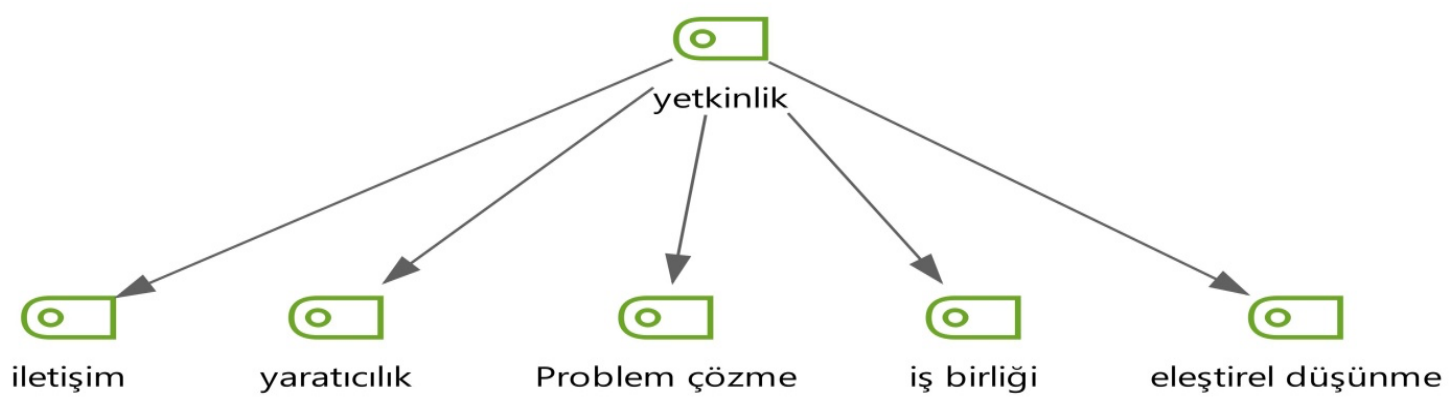

Şekil 3. Programda en çok yer alan yetkinlik özellikleri

Şekil 3'te görüldügü gibi programda en fazla yer alan yetkinlik özellikleri iletişim, yaratıc1lık, problem çözme becerisi, iş birliği ve eleştirel düşünme olmuştur.
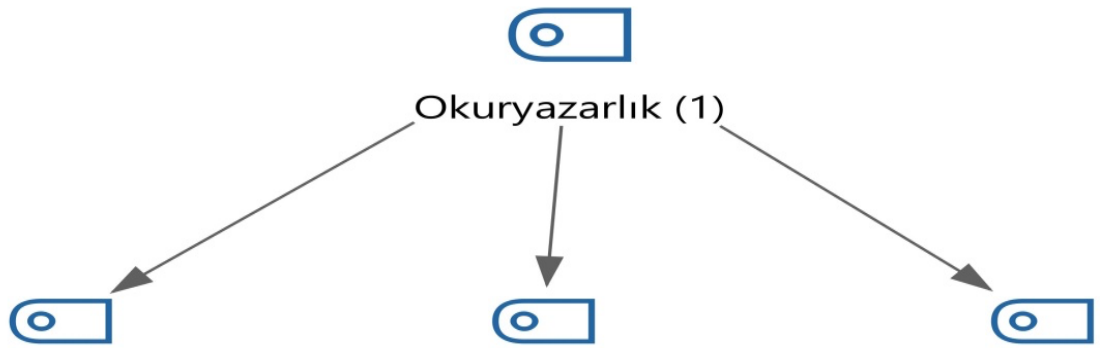

bilimsel okuryazarlık (O) medya okuryazarlığı (O) teknoloji okuryazarlığı (O)

Şekil 4. Programda okuryazarlık becerilerinin yer alma durumu

Şekil 4'te görüldüğü gibi programda okuryazarlık ifadesi sadece bir defa yer almış, bilimsel okuryazarlık, medya okuryazarlığı ve teknoloji okuryazarlığı ile ilgili hiçbir bilgi yer almamıştır. 


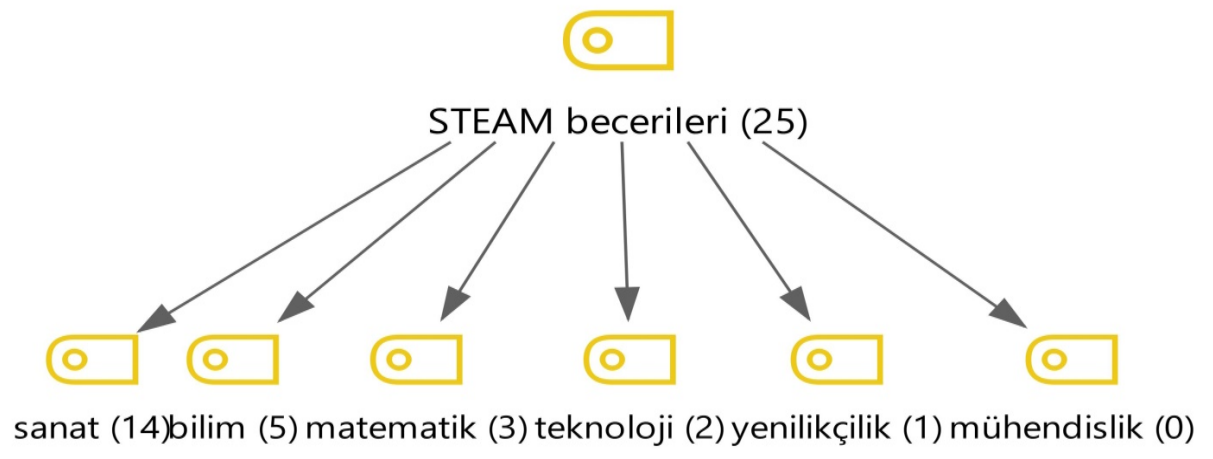

Şekil 5. STEAM becerilerinin programda yer alma durumu

Şekil 5'te görüldüğü gibi STEAM becerileri ile ilgili kavramlar ve çalışmalar daha çok sanat alanında yoğunlaşırken programın matematik ve teknoloji konusunda zayıf kaldığı ve mühendislik, yenilikçilik ve tasarım konularını içermediği görülmektedir.

Tablo 1. Okul öncesi eğitim programında 21. yy becerileri ve STEAM ile ilgili ifadelerden örnekler

\begin{tabular}{|c|c|}
\hline Beceriler & Açıklamalar \\
\hline $\begin{array}{c}\text { Karakter } \\
\text { özellikleri/Girişimcilik }\end{array}$ & $\begin{array}{l}\text { "Çocukların bağımsız davranışlar geliştirmesi desteklenmeli, yardıma gereksinim duyduklarında yetişkin } \\
\text { desteği, rehberliği ve yetişkinin güven verici yakınlığı sağlanmalıdır (2013 okul öncesi eğitim programı word, } \\
\text { Konum 140)" }\end{array}$ \\
\hline $\begin{array}{l}\text { Karakter } \\
\text { özellikleri/Girişimcilik } \\
\text { Yetkinlik/İletişim }\end{array}$ & $\begin{array}{l}\text { Çocuğun sağlıklı bir şekilde büyüyebilmesi, gelişebilmesi ve öğrenmeye karşı olumlu tutumlar geliştirebilmesi } \\
\text { için nitelikli bilişsel uyarıcıların, zengin dil etkileşimlerinin, olumlu sosyal ve duygusal deneyimlerin çocuğa } \\
\text { sunulduğu ve çocuğun bağımsızlığının desteklendiği bir çevrenin yaratılmasına ihtiyaç vardır. (2013 okul } \\
\text { öncesi eğitim programı word, Konum 155) }\end{array}$ \\
\hline $\begin{array}{l}\text { Karakter } \\
\text { özellikleri/Girişimcilik- } \\
\text { Sorgulama } \\
\text { Yetkinlik/İletişim }\end{array}$ & $\begin{array}{l}\text { Öğretmenlerin, öğrenme sürecinde çocukların plan yapmalarına, uygulamalarına, düzenlemelerine, } \\
\text { sorgulamalarına, araştırmalarına, tartışmalarına ve üretmelerine mümkün olduğu kadar çok olanak } \\
\text { tanımaları gerekmektedir. Çocuğun okula, ögrenmeye ve araştırmaya dair olumlu tutumlar kazanabilmesi için; } \\
\text { olumlu benlik algisı geliştirmesi, kendini değerli hissetmesi, akran ve öğretmenleriyle karşılıklı etkileşime } \\
\text { girebilmesi önemlidir. (2013 okul öncesi eğitim programı word, Konum 177) }\end{array}$ \\
\hline $\begin{array}{r}\text { Karakter özelli } \\
\text { Araştı }\end{array}$ & $\begin{array}{l}\text { Keşfederek öğrenmede çocuğun öğrenme sürecine etkin katılması, öğrendiklerini farklı durumlara transfer } \\
\text { etmesi ve yeni durumlarda kullanması önemlidir. Program çocuğun çevresinde olanları fark etmesini, merak } \\
\text { ettiği konulara ilişkin sorular sormasını, araştırmasını, keşfetmesini ve oynayarak öğrenmesini teşvik eder. } \\
\text { Böylece ezbere dayalı öğrenme yerine anlamlı öğrenme gerçekleşmiş olur. (2013 okul öncesi eğitim programı } \\
\text { word, Konum 193) }\end{array}$ \\
\hline $\begin{array}{r}\text { Yetkinlik/ Prob } \\
\text { Yaratıc }\end{array}$ & $\begin{array}{l}\text { Problem durumlarına çözüm üretir. (Göstergeleri: Problemi söyler. Probleme çeşitli çözüm yolları önerir. } \\
\text { Çözüm yollarından birini seçer. Seçtiği çözüm yolunun gerekçesini söyler. Seçtiği çözüm yolunu dener. Çözüme } \\
\text { ulaşamadığı zaman yeni bir çözüm yolu seçer. Probleme yaratıcı çözüm yolları önerir. (2013 okul öncesi } \\
\text { eğitim programı word, Konum 268) }\end{array}$ \\
\hline $\begin{array}{r}\text { STE } \\
\text { Yetkinli }\end{array}$ & $\begin{array}{l}\text { Çocukların özgün özellikler taşıyan ürün oluşturması; duygularını, düşüncelerini ve hayallerini tamamen } \\
\text { kendine özgü bir biçimde çalışmasına yansıtıp, yaratıcılığını kullanarak ürününü diğerlerininkinden farklı } \\
\text { kılmasıdır. Bu amaçla, nesneleri alışılmışın dışında farklı şekillerde kullanabilecekleri, duygularını drama, } \\
\text { oyun, dans, resim, müzik, şiir, öykü gibi yollarla gösterebilecekleri etkinlikler planlanmalıdır. Öğretmenin } \\
\text { çocukların özgün ürün yapmasını beklemesinin yanı sıra onları değişik sanat dalları ile tanıştırması da önemlidir. } \\
\text { Bu tanışma çevrenin olanakları elverdiğince gerçekleştirilebilir. Örneğin, resim veya heykel galerileri, müzeler, } \\
\text { tarihî yerler ve binalar ziyaret edilebilir, bir ressam veya hasır dokuma ustası sınıfa davet edilebilir veya } \\
\text { atölyesinde ziyaret edilebilir (2013 okul öncesi eğitim programı word, Konum 315) }\end{array}$ \\
\hline STE & $\begin{array}{l}\text { Çocukların bilimsel süreç becerilerini geliştirebilecekleri bu merkez, aydınlık olmalı, rahat çalışılabilecek } \\
\text { şekilde düzenlenmeli ve görece sessiz merkezlere yakın olmalıdır. (2013 okul öncesi eğitim programı word, } \\
\text { Konum 436) }\end{array}$ \\
\hline STEAM / I & $\begin{array}{l}\text { tematik eğitimi, çocuğun bilişsel gelişimine katkı sağlamak, çocuklarda matematiğe karşı olumlu bir } \\
\text { um kazandırmak, çocukların önceden getirdikleri kavramsal bilgilerle yeni bilgiler arasında bağ kurmasına } \\
\text { dımcı olmak, matematiksel kavramların neden ve nasıl kullanıldığını anlamaya yardımcı olmak amacını } \\
\text { Imaktadır. (2013 okul öncesi eğitim programı word, Konum 455) }\end{array}$ \\
\hline $\begin{array}{l}\text { Okuryazarlık/ Temel } \\
\text { okuryazarlık }\end{array}$ & $\begin{array}{l}\text { Okuma yazmaya hazırlık çalışmaları sadece masa başında yapilan kitap/kavram/çizgi çalışmaları olarak } \\
\text { değerlendirilmemelidir. Aksine, bu çalışmalar birçok farklı etkinlik çeşidi ile (sanat, drama, müzik, oyun vb.) } \\
\text { gerçekleştirilmelidir. } \\
\text { (2013 okul öncesi eğitim programı word, Konum 468) }\end{array}$ \\
\hline $\begin{array}{l}\text { STEAM/ Sanat } \\
\text { Karakter özellikleri/ } \\
\text { Kültürel farkındalık } \\
\text { Yetkinlik/ İletişim- } \\
\text { Yaratıcıllk }\end{array}$ & $\begin{array}{l}\text { Çocuğun yaratıcılığını ve hayal gücünü kullanarak problem çözmesine, eleştirel ve çözüm odaklı } \\
\text { düşünmesine olanak tanıyan etkinliklerdir. Sanat etkinlikleri aynı zamanda çocukların kendilerini ifade ederek } \\
\text { iletişim becerilerini geliştirmesine yardımcı olur. Bunlara ek olarak sanat etkinlikleri çocuğun kendini, içinde } \\
\text { bulunduğu kültü̈ü ve diğer kültürleri daha iyi anlamasına olanak tanıyarak farklılıklara saygı duymasına da } \\
\text { yardımcı olur. (2013 okul öncesi eğitim programı word, Konum 486) }\end{array}$ \\
\hline
\end{tabular}


Yukarıda Tablo 1'de görüldüğü gibi 2013 okul öncesi eğitim programında yer alan karakter özellikleri, yetkinlik, STEAM ve okuryazarlık ile ilgili ifadelerden alıntılar verilmiştir. Bu bilgilerin programın amacı ve önemi, programın temel özellikleri, gelişim, kazanım ve göstergeler, okul öncesi eğitim ortamı ve öğrenme merkezleri, etkinlik çeşitleri ve açıklamaları kısımlarında yer aldığı görülmüştür.

\section{Tartışma, Sonuç ve Öneriler}

Yapılan araştırma sonucunda okul öncesi eğitim programının 21. yy becerileri içerisinde en fazla girişimcilik, sorumluluk, kültürel farkındalık ve araştırma üzerinde durduğu görülmektedir. Çocuklarda yetkinlik becerisini geliştirmeye baktığımızda ise en fazla iletişim, yaratıcılık ve problem çözme becerisi üzerinde durulduğu görülmektedir. Alismail ve McGuire (2015) yaptıkları araştırmada 21. yy becerilerinin eğitim programına alınmasının çocuklar için hayati olan becerilerin kazanılması ve gelecekte başarılı olmaları için önemli olduğu sonucuna ulaşmışlardır. Çelebi ve Altuncu (2019) yaptıkları araştırmada çocuklara 21. yy becerilerinin kazandırılması için programda yer alacak kazanımlarla birlikte, materyallerin hazırlanması ve öğretmenlerin 21 yy becerilerine sahip olma durumlarının araştırılması ve bu konuda eğitilmeleri gerektiğini ifade etmişlerdir. Ayrıca, Larson ve Miller (2011) 21 yy becerilerinin eğitim müfredatına dâhil edilmesiyle eğitimin öğrencilere daha ilgi çekici hale getirilebileceği ve yeni öğrenme fırsatlarının yaratılacağını ifade etmişlerdir. Greenhill (2010) 21. yy becerilerine sahip bir programın çocukları derin düşünmeye sevk etmesi gerektiği, araştırma temelli çalışmaları desteklemesi ve teknoloji kullanımının programın parçası olması gerektiğini ifade etmiştir. Cansoy (2018) 21. yy becerilerinin daha çok öğrenci odaklı ve öğrencinin potansiyelini ortaya çıkarmaya yönelik olması gerektiğini ifade etmiştir. Ancak programa bakıldığında teknoloji kullanımının yetersiz olduğu ve çocukları derin düşünmeye sevk edecek merak ve proje tabanlı uygulamaların yeterli olmadığ1 görülmektedir. Nitekim, Gelen (2017) yaptığı araştırmada 21. yy becerilerinin mevcut programlar içerisinde çok yetersiz ve dağınık olduğu ve bu becerilerin eğitim sistemi içerisindeki rolünün net olarak anlaşılamadığını ifade etmiştir. Tutkun (2010) ise yaptığı araştırmada eğitim programlarında disiplinler arası ilişkilerin yüksek düzeyde olması, öğretmenlerin program hazırlama sürecine katılımının sağlanması ve eğitim programlarında çok kültürlülüğe yer verilmesi gerektiğini ifade etmiş̧tir. Bu anlamda Okul öncesi eğitim programının kültürel farklılıklara yönelik içeriğe sahip olduğu ve öğretmenlerin programın hazırlanma sürecine dâhil edildiği söylenebilir.

Okuryazarlık becerisini programda bir defa geçtiği bunun dışında bilgi, medya ve teknoloji okuryazarlığının programda yer almadığı görülmüştür. Benzer bir çalışmada, Kayhan, Altun ve Gürol (2019) Türkçe programını 21. yy becerileri açısından incelemiş ve programın bilgi, teknoloji ve medya okuryazarlığı bağlamında yetersiz olduğu sonucuna ulaşmışlardır. Breivik (2005) öğrencilerin bilgiye ulaşması, tanımlaması, değerlendirmesi ve etkili kullanabilmesi için bilgiyi nerede ve nasıl bulabileceğine ilişkin kritik düşünme becerilerinin kazandırılması gerektiğini ifade etmiştir. Dolayısıyla bugünün dünyasında başarılı öğrenciler yetiştirmek için bilgi okuryazarlığı paydaşlar arasında iş birliği sağlanarak müfredata alınmalıdır.

STEAM becerilerinin yoğunluklu olarak sanat eğitimi şeklinde yer aldığı, bilim ve matematik becerilerinin programda yer aldığı ancak mühendislik, tasarım ve yenilikçiliğin programda yer almadığı görülmüştür. Benzer olarak Akgündüz ve Akpınar (2018) okul öncesinde STEM uygulama örneklerinin oldukça sınırlı olduğunu ifade etmişlerdir. Polat ve Bardak (2019) yaptıkları araştırmada çocukların ihtiyacı olan çalışma ve yaşam becerilerini kazanabilmeleri için erken yaşlarda STEM yaklaşımının eğitim sürecine dâhil edilmesi gerektiği sonucuna ulaşmışlardır. Benzer olarak, Hackey (2020) çocukların başarısı için erken çocukluk yıllarında STEM eğitiminin teşvik edilmesi gerektiğini ifade etmiştir. Bu noktada, STEM yaklaşımına uygun programların oluşturulması ve öğretmenler tarafindan uygulanması gerektiği ifade edilebilir. Koyunlu-Ünlü ve Dere (2019) yaptıkları araştırmada okul öncesi eğitimi öğretmenlerinin STEM farkındalıklarının arttırılması için laboratuvar uygulamaları, atölye çalışmaları gibi okul öncesi öğretmenlerinin bilgi ve becerilerinin arttırılacağı çalışmaların yapılması gerektiğini ifade etmişlerdir. Kennedy ve Odell (2014) öğretmenlerin etkili bir STEM eğitimi verebilmeleri için yenilikçi öğretim materyalleri kullanmaları gerektiğini söylemişlerdir. Öğretmenler uygun materyallere sahip olursa uygulamalı ve işbirlikli öğrenme ortaya çıkar. Öğretimin etkili olması için STEM uygulamalarının, günlük etkinlikler, sınıf ortamı, öğretim yöntemleri ve müfredata dâhil edilmesi gerektiğini ifade etmişlerdir. Rockland ve diğerleri (2010) öğretmenlerin bilim ve matematik konusunda eğitildiği ancak programda mühendislik becerilerine yer verilmediğini ifade etmişlerdir. Bundan dolayı öğretmenlere mühendislik becerilerinin geliştirilmesi ve eğitim sürecinde kullanabilmesi için hizmet içi eğitimlerin verilmesi gerektiğini ifade etmişlerdir.

Öneri olarak, Uyanık-Balat ve Günşen (2017)'in de ifade ettiği gibi MEB'in güncelleyeceği ya da yeniden hazırlayacağı okul öncesi eğitim programında, 21. yy becerileri dengeli ve yapılandırılmış bir şekilde program içerisinde yer alabilir ve STEM eğitimine tasarım, mühendislik ve yenilikçiliğin yer alacağı şekilde daha fazla önem verilebilir. 


\section{Kaynakça / References}

Akgündüz, D., \& Akpınar, B. C. (2018). Okul öncesi eğitiminde STEM uygulamaları. D. Akgündüz (Ed.), Okul öncesinden üniversiteye kuram ve uygulamada STEM eğitimi içinde (ss. 135-167). Ankara: Anı Yayıncılık.

Alismail, H. A., \& McGuire, P. (2015). 21st century standards and curriculum: Current research and practice. Journal of Education and Practice, 6(6), 150-154.

Aral, N., \& Kadan, G. (2018). 2013 Okul Öncesi Eğitim Programının değerler eğitimi bağlamında incelenmesi. Erken Çocukluk Çalışmaları Dergisi, 2(1), 113-131.

Beers, S. Z. (2011). 21st century skills: Preparing students for their future. Access: https://cosee.umaine.edu/files/coseeos/21st_century_skills.pdf

Bertrand, M. G. (2019). STEAM education in Ontario, Canada: A case study on the curriculum and instructional models of Four K-8 STEAM Programs (Unpublished master thesis). The University of Western Ontario, Canada.

Breivik, P. S. (2005). 21st century learning and information literacy. Change: The Magazine of Higher Learning, 37(2), 21-27.

Büyüköztürk, Ş., Kılıç-Çakmak, E., Akgün, E. Ö., Karadeniz, Ş. \& Demirel, F. (2012). Bilimsel araştırma yöntemleri. Ankara: Pegem Akademi Yayıncilı.

Cansoy, R. (2018). Uluslararası çerçevelere göre 21. yüzyıl becerileri ve eğitim sisteminde kazandırılması. İnsan ve Toplum Bilimleri Araştırmaları Dergisi, 7(4), 3112-3134.

Creswel, J. W. (2009). Research design: Qualitative, quantitative, and mixed methods approaches. Los Angeles, CA: University of Nebraska-Lincoln.

Çelebi, M., \& Altuncu, N. (2019). 21. yüzyıl becerilerinin İngilizce Öğretim Programındaki yeri. 6. Uluslararası Multidisipliner Çalı̧̧maları Kongresi Bildiriler Kitabı (ss. 231-244). 26-27 Nisan, Gaziantep, Türkiye.

Deniz, Ü., \& Yıldız, R. (2018). Milli Eğitim Bakanlığı Okul Öncesi Eğitim Programında cinsel gelişim ve cinsel eğitim. Gazi University Journal of Gazi Educational Faculty (GUJGEF), 38(2), 431-447.

Fraenkel, J. R., Wallen, N. E., \& Hyun, H. H. (2011). How to design and evaluate research in education. New York, NY: McGrawHill.

Gelen, İ. (2017). P21-program ve öğretimde 21. yüzyıl beceri çerçeveleri (ABD Uygulamaları). Disiplinlerarası Eğitim Araştırmalarl Dergisi, 1(2), 15-29.

Greenhill, V. (2010). 21st century knowledge and skills in educator preparation: Partnership for 21 st century skills. Access: https://files.eric.ed.gov/fulltext/ED519336.pdf

Gülay, H., \& Ekici, G. (2010). MEB Okul Öncesi Eğitim Programının çevre eğitimi açısından analizi. Türk Fen Eğitimi Dergisi, 7(1), 74-84.

Gürkan, K., \& Koran, N. (2014). 36-72 aylık çocuklar için okul öncesi eğitim programının çocuğun katılım hakkına yer verme durumu açısından incelenmesi. Journal of Teacher Education and Educators, 3(2), 203-226.

Hachey, A. C. (2020). Herkes için başarı: Erken çocukluk dönemi STEM kimliğini teşvik etmek. Uluslararası Alan Eğitimi Dergisi, 6(1), 201-208.

Häkkinen, P., Järvelä, S., Mäkitalo-Siegl, K., Ahonen, A., Näykki, P., \& Valtonen, T. (2017). Preparing teacher-students for twentyfirst-century learning practices (PREP 21): A framework for enhancing collaborative problem-solving and strategic learning skills. Teachers and Teaching, 23(1), 25-41.

Jamil, F. M., Linder, S. M., \& Stegelin, D. A. (2018). Early childhood teacher beliefs about STEAM education after a professional development conference. Early Childhood Education Journal, 46(4), 409-417.

Katz, L. G. (2010). STEM in the early years. Early Childhood Research And Practice, 12(2), 11-19.

Kayhan, E., Altun, S., \& Gürol, M. (2019). Sekizinci Sınıf Türkçe Öğretim Programı (2018)'nın 21. yüzyıl becerileri açısından değerlendirilmesi. Adnan Menderes Üniversitesi Eğitim Fakültesi Ĕ̈itim Bilimleri Dergisi, 10(2), 20-35. 
Kennedy, T. J., \& Odell, M. R. L. (2014). Engaging students in STEM education. Science Education International, $25(3), 246-258$.

Kereluik, K., Mishra, P., Fahnoe, C., \& Terry, L. (2013). What knowledge is of most worth: Teacher knowledge for 21st century learning. Journal of Digital Learning in Teacher Education, 29(4), 127-140.

Koyunlu-Ünlü, Z., \& Dere, Z. (2019). Okul öncesi öğretmen adaylarının FeTeMM farkındalıklarının değerlendirilmesi. Erzincan Üniversitesi Eğitim Fakültesi Dergisi, 21(1), 44-55.

Lamb, S., Maire, Q., \& Doecke, E. (2017). Key skills for the 21st century: An evidence-based review. Sydney: NSW Department of Education.

Larson, L. C., \& Miller, T. N. (2011). 21st century skills: Prepare students for the future. Kappa Delta Pi Record, 47(3), 121-123.

McClure, E. R., Guernsey, L., Clements, D. H., Bales, S. N., Nichols, J., Kendall-Taylor, N., \& Levine, M. H. (2017). STEM starts early: Grounding science, technology, engineering, and math education in early childhood. New York, NY: Joan Ganz Cooney Center (Sesame Workshop).

Merriam, S. B., \& Tisdell, E. J. (2015). Qualitative research: A guide to design and implementation. Toronto: John Wiley \& Sons.

National Center On. (2018). Understanding STEAM and how children use it. Access: https://eclkc.ohs.acf.hhs.gov/sites/default/files/pdf/steam-ipdf.pdf

OECD. (2018). The future of education and skills: Education 2030: The future we want. Access: https://www.oecd.org/education/2030/E2030\%20Position\%20Paper\%20(05.04.2018).pdf

O’Neal, L. J., Gibson, P., \& Cotten, S. R. (2017). Elementary school teachers' beliefs about the role of technology in 21 st-century teaching and learning. Computers in the Schools, 34(3), 192-206.

Partnership for 21st Century Skills. (2008). 21st century skills, education and competitiveness: A resource and policy guide. Washington, DC: Partnership for 21st Century Skills.

Polat, Ö., \& Bardak, M. (2019). Erken çocukluk döneminde STEM yaklaşımı. International Journal of Social Science Research, 8(2), 18-41.

Rockland, R., Bloom, D. S., Carpinelli, J., Burr-Alexander, L., Hirsch, L. S., \& Kimmel, H. (2010). Advancing the 'E' in K-12 STEM education. The Journal of Technology Studies, 36(1), 53-64.

Sapsağlam, Ö. (2013). Değerlendirme boyutuyla okul öncesi eğitim programları (1952- 2013). Uluslararası Türk Eğitim Bilimleri Dergisi, 2013(1), 63-73.

Soylu, S. (2016). STEM education in early childhood in Turkey. Journal of Educational and Instructional Studies in the World, 6, 38-47.

Sönmez, S., \& Seyhan, G. B. (2016). MEB 2013 Okul Öncesi Eğitim Programının sağlık kavramı açısından incelenmesi. Turkish Online Journal of Qualitative Inquiry, 7(1), 146-174.

Tsupros, N., Kohler, R., \& Hallinen, J. (2009). STEM education: A project to identify the missing components. Intermediate Unit, 1, $11-17$.

Tuğluk, M. N., \& Özkan, B. (2019). MEB 2013 Okul Öncesi Eğitim Programının 21. yüzyıl becerileri açısından analizi. Temel Eğitim Dergisi, 1(4), 29-38.

Tutkun, Ö. F. (2010). 21. yüzyılda eğitim programının felsefi boyutları. Gazi Eğitim Fakültesi Dergisi, 30(3), 993-1016.

Uğraş, M. (2017). Okul öncesi öğretmenlerinin STEM uygulamalarına yönelik görüşleri. Eğitimde Yeni Yaklaşımlar Dergisi, 1(1), 39-54.

Uyanık-Balat, G., \& Günşen, G. (2017). Okul öncesi dönemde STEM yaklaşımı. Akademik Sosyal Araştırmalar Dergisi, 5(42), 337-348.

Voogt, J., \& Roblin, N. P. (2012). A comparative analysis of international frameworks for 21st century competences: Implications for national curriculum policies. Journal of Curriculum Studies, 44(3), 299-321. 
Yalçın, S. (2018). 21. yüzyıl becerileri ve bu becerilerin ölçülmesinde kullanılan araçlar ve yaklaşımlar. Ankara Üniversitesi Eğitim Bilimleri Fakültesi Dergisi, 51(1), 183-201.

Yaşar-Ekici, F., Bardak, M., \& Yousef-Zadeh, M. (2018). Erken çocukluk döneminde STEM. K. A. Kırkıç \& E. Aydın (Ed.), Merhaba STEM yenilikçi bir ögretim yaklaşımı içinde (ss. 51-78). Konya: Eğitim Yayınevi.

Yıldırım, A., \& Şimşek, H. (2013). Sosyal bilimlerde nitel araştırma yöntemleri. Ankara: Seçkin Yayıncılık. 